Article

\title{
Strain-Dependent Adsorption of Pseudomonas aeruginosa- Derived Adhesin-Like Peptides at Abiotic Surfaces
}

\author{
Yu Yang, Sabrina Schwiderek, Guido Grundmeier (D) and Adrian Keller *(D) \\ Technical and Macromolecular Chemistry, Paderborn University, Warburger Str. 100, 33098 Paderborn, Germany; \\ yuyang@mail.uni-paderborn.de (Y.Y.); sschwid2@mail.uni-paderborn.de (S.S.); \\ g.grundmeier@tc.uni-paderborn.de (G.G.) \\ * Correspondence: adrian.keller@uni-paderborn.de
}

Citation: Yang, Y.; Schwiderek, S.; Grundmeier, G.; Keller, A.

Strain-Dependent Adsorption of Pseudomonas aeruginosa-Derived Adhesin-Like Peptides at Abiotic Surfaces. Micro 2021, 1, 129-139. https://doi.org/10.3390/ micro1010010

Academic Editor: Giulia Ronchi

Received: 15 June 2021

Accepted: 27 July 2021

Published: 31 July 2021

Publisher's Note: MDPI stays neutral with regard to jurisdictional claims in published maps and institutional affiliations.

Copyright: (c) 2021 by the authors. Licensee MDPI, Basel, Switzerland. This article is an open access article distributed under the terms and conditions of the Creative Commons Attribution (CC BY) license (https:// creativecommons.org/licenses/by/ $4.0 /)$.
Abstract: Implant-associated infections are an increasingly severe burden on healthcare systems worldwide and many research activities currently focus on inhibiting microbial colonization of biomedically relevant surfaces. To obtain molecular-level understanding of the involved processes and interactions, we investigate the adsorption of synthetic adhesin-like peptide sequences derived from the type IV pili of the Pseudomonas aeruginosa strains PAK and PAO at abiotic model surfaces, i.e., $\mathrm{Au}, \mathrm{SiO}_{2}$, and oxidized Ti. These peptides correspond to the sequences of the receptor-binding domain 128-144 of the major pilin protein, which is known to facilitate P. aeruginosa adhesion at biotic and abiotic surfaces. Using quartz crystal microbalance with dissipation monitoring (QCM-D), we find that peptide adsorption is material- as well as strain-dependent. At the Au surface, PAO(128-144) shows drastically stronger adsorption than PAK(128-144), whereas adsorption of both peptides is markedly reduced at the oxide surfaces with less drastic differences between the two sequences. These observations suggest that peptide adsorption is influenced by not only the peptide sequence, but also peptide conformation. Our results furthermore highlight the importance of molecular-level investigations to understand and ultimately control microbial colonization of surfaces.

Keywords: adsorption; peptide; microbial adhesion; biofilm; quartz crystal microbalance

\section{Introduction}

The past century has seen a continuous increase in the number of surgical procedures aimed at the restoration of body functions via the implantation of artificial biomaterials. While tremendous advances in the fields of reconstructive medicine and biomaterials science and engineering have resulted in highly efficient implants with low probability of rejection by the body, implant-associated infections have developed into a serious problem over the last two decades [1]. All implants from heart valves and prosthetic joints to vascular prostheses and dental implants attract microorganisms and thus exhibit a certain risk of deep infection [2]. Due to the rapid spreading of antimicrobial-resistant pathogens [3-5], implant-associated infections represent an increasingly severe burden on healthcare systems worldwide. For the US alone, it was estimated that the total number of infected total hip and total knee arthroplasties will increase from 8326 in 2010 to 37,059 in 2030 , corresponding to additional costs resulting only from these two procedures of up to US\$ 5 billion [6]. Suppressing implant-associated infections via the rational engineering of implant surfaces to render them resistant to microbial colonization has thus become a very important goal in the field of biomedical materials research [7]. For such engineering strategies to succeed, however, a detailed understanding of the molecular mechanisms that govern microbial colonization of abiotic surfaces is required.

One of the most common nosocomial pathogens encountered in healthcare settings all over the world is the Gram-negative bacterium Pseudomonas aeruginosa. P. aeruginosa infections are particularly hard to treat and associated with exceptionally high mortality 
rates [8]. This is because of the intrinsic high resistance of $P$. aeruginosa to many antimicrobials and its remarkable ability to acquire additional mechanisms of resistance to multiple groups of antimicrobials [9]. Pandrug-resistant strains that do not respond to any available antimicrobial are an increasing problem worldwide [8,9]. Consequently, in 2017, carbapenem-resistant $P$. aeruginosa was ranked second on the WHO priority list of antimicrobial-resistant bacteria [10].

When colonizing surfaces, $P$. aeruginosa relies predominantly on dynamic protein filaments called type IV pili (see Figure 1a) that facilitate initial adhesion as well as migration and motility of the adhering bacteria [11-13]. Each of these filaments is anchored in the inner membrane and consists of several thousand copies of a single protein subunit called pilin (see Figure $1 b$ ). These type IV pilins are structurally highly conserved in different $P$. aeruginosa strains and also other bacteria [12-15]. Of particular medical importance is the C-terminal D-region, which contains a loop structure defined by a disulfide bridge (see Figure 1b) and facilitates adherence to host-cell epithelia [12,13]. However, Giltner et al. demonstrated that this receptor-binding domain between residues 128 and 144 is also involved in P. aeruginosa adhesion to abiotic surfaces and in particular stainless steel, polystyrene, and polyvinylchloride [14]. Therefore, in this work, we investigate the adsorption of synthetic peptide sequences corresponding to the receptor-binding domains of $P$. aeruginosa pilins at abiotic model surfaces, i.e., $\mathrm{Au}, \mathrm{SiO}_{2}$, and oxidized $\mathrm{Ti}\left(\mathrm{TiO}_{\mathrm{x}} / \mathrm{Ti}\right)$. While $\mathrm{Au}$ is used as a well-defined, inert reference surface, $\mathrm{SiO}_{2}$ and $\mathrm{TiO}_{\mathrm{x}} / \mathrm{Ti}$ films serve as model surfaces for implants based on bioactive glasses [16] and titanium alloys [17], respectively. Since the receptor-binding domain shows considerable sequence variability between different $P$. aeruginosa strains, we are comparing the adsorption of two peptides derived from two different strains, i.e., PAK and PAO (see Figure 1c). Using quartz crystal microbalance with dissipation monitoring (QCM-D), we find that peptide adsorption is not only surface-dependent, but also strain-dependent. In particular, $\mathrm{PAO}(128-144)$ shows stronger adsorption at Au surfaces than PAK(128-144), whereas at the oxide surfaces, adsorption of both peptides is markedly reduced and almost negligible. Our results suggest that peptide adsorption at these surfaces is influenced not only by the peptide sequence, but also the peptide loop conformation and stability.

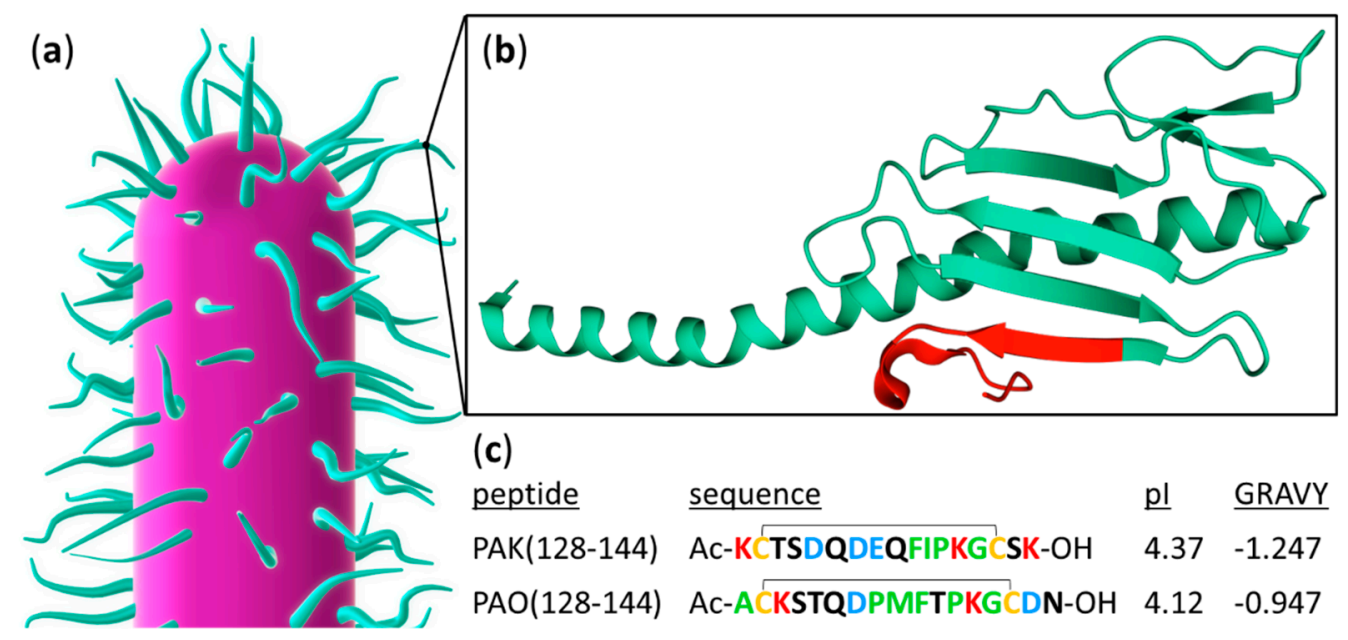

Figure 1. (a) Schematic representation of P. aeruginosa with cell surface-associated type IV pili. (b) Structure of the major PAK pilin protein taken from the RCSB PDB (rcsb.org), PDB ID 1OQW [15]. The C-terminal receptor-binding domain PAK(128-144) is highlighted in red. The image was created using Mol* Viewer [18]. (c) Sequences, isoelectric points (pI, calculated using Pep-Calc.com [19]), and grand average of hydropathicity (GRAVY, calculated using the Expasy ProtParam tool [20]) of the pilin-derived peptides used in this work. Positively charged amino acids are indicated in red, negatively charged ones in blue, and hydrophobic ones in green. Cysteines are colored orange with disulfide bridges indicated. 


\section{Materials and Methods}

\subsection{Peptide Sample Preparation}

PAK(128-144) and PAO(128-144) were purchased from the Biomolecular Synthesis Facility of the Center For Molecular And Cellular Bioengineering, TU Dresden, Germany, and used without further purification. The peptides were dissolved in phosphate buffered saline (PBS, Sigma-Aldrich, Steinheim, Germany) containing $10 \mathrm{mM} \mathrm{Na}_{2} \mathrm{HPO}_{4}, 1.8 \mathrm{mM}$ $\mathrm{KH}_{2} \mathrm{PO}_{4}, 138 \mathrm{mM} \mathrm{NaCl}$, and $2.7 \mathrm{mM} \mathrm{KCl}$ with a pH value of 7.4. To avoid bubble formation during the QCM-D measurements, the buffer solution was degassed with Ar for $1 \mathrm{~h}$. The final peptide concentration was $100 \mu \mathrm{M}$ in each case. For all solutions, HiPerSolv Chromanorm water for HPLC (VWR International, Fontenay-sous-Bois, France) was used.

\subsection{Surface Preparation}

Gold-coated QCM-D crystals with a fundamental resonance frequency of $4.95 \mathrm{MHz}$ were purchased from Fil-Tech Inc., Boston, MA, USA. Before use, the sensors were cleaned with freshly prepare RCA1 solution (1:1:5 $\left.\mathrm{NH}_{4} \mathrm{OH}: \mathrm{H}_{2} \mathrm{O}_{2}: \mathrm{H}_{2} \mathrm{O}\right)$ at $75^{\circ} \mathrm{C}$ for $30 \mathrm{~s}$. Afterwards, the sensors were rinsed with water and ethanol and dried in a stream of ultrapure air. The cleaned surface of the Au electrode was either used as is in the subsequent adsorption experiments or coated with $\mathrm{SiO}_{2}$ and $\mathrm{Ti}$ as described below.

A thin film of Ti was deposited on the cleaned Au surface on the QCM-D sensor as previously described [21]. In brief, RF-magnetron sputter deposition (Ion'X-2" UHV from Thin Film Consulting, Grafenberg, Germany, with a BDS-HF 300 AFP generator from BDISCOM SRL, Vellezzo Bellini, Italy) was performed under normal incidence at room temperature in a vacuum chamber with a base pressure of $\sim 10^{-7} \mathrm{mbar}$. A high-purity Ti target (purity 99.995\%, EVOCHEM, Offenbach am Main, Germany) was used. During deposition, an Ar flow rate of $30 \mathrm{sccm}$ was applied, resulting in a Ti deposition rate of $0.07 \AA / \mathrm{s}$. The total applied film thickness was $100 \mathrm{~nm}$.

$\mathrm{SiO}_{2}$ was deposited using reactive RF-magnetron sputter deposition (Nexdep physical vapor deposition system, Angstrom Engineering Inc., Kitchener, ON, Canada, base pressure $\sim 5 \times 10^{-7} \mathrm{mbar}$ ). First, $10 \mathrm{~nm}$ of Ti (purity $99.995 \%$, Angstrom Engineering Inc., Kitchener, ON, Canada) were deposited as an adhesion layer at an Ar flow rate of $20 \mathrm{sccm}$ and a deposition rate of $0.10 \AA / \mathrm{s}$. Then, $100 \mathrm{~nm}$ of $\mathrm{SiO}_{2}$ were deposited by sputtering a Si target (undoped, purity 99.999\%, Angstrom Engineering Inc., Kitchener, ON, Canada) using a gas mixture of $20 \mathrm{sccm}$ Ar and $1 \mathrm{sccm} \mathrm{O}_{2}$. The resulting deposition rate was $0.16 \AA / \mathrm{s}$.

\subsection{X-ray Photoelectron Spectroscopy (XPS)}

The surface chemistry of the $\mathrm{SiO}_{2}$ and $\mathrm{TiO}_{x} / \mathrm{Ti}$ films was characterized by means of $\mathrm{X}$-ray photoelectron spectroscopy (XPS). All measurements were done with an Omicron ESCA+ system (Omicron NanoTechnology, Taunusstein, Germany). The pressure was below $3 \times 10^{-10}$ mbar and monochromatic $\mathrm{Al} \mathrm{K} \alpha$ radiation $(1486.7 \mathrm{eV})$ was used. The measurements were carried out at a take-off angle of $30^{\circ}$ with respect to the surface plane. The survey and core level spectra were detected with a pass energy of $100 \mathrm{eV}$ and $20 \mathrm{eV}$, respectively. During the measurements, neutralization with a beam energy of $5.0 \mathrm{eV}$ and an emission current of $10.0 \mu \mathrm{A}$ was performed. The evaluation of the spectra was done with CasaXPS, V 2.3 (Casa Software Ltd., Teignmouth, UK). The spectra were calibrated to the aliphatic C1s peak at $284.6 \mathrm{eV}$. The background of the spectra was subtracted with a Shirley type function and for the peak fitting Gaussian and Lorentzian peak shapes with $30 \%$ of Lorentzian contribution were used.

\subsection{Atomic Force Microscopy (AFM)}

The topographies of all surfaces were analyzed by atomic force microscopy (AFM) using a JPK NanoWizard 3 (JPK GmbH, Berlin, Germany) and HQ:NSC15/AlBS cantilevers (MikroMasch, Wetzlar, Germany) in intermittent contact mode in air. The images had a size of $5 \times 5 \mu^{2}$ and a resolution of $1024 \times 1024 \mathrm{px}$. All AFM images were processed using Gwyddion (version 2.51) [22] and the RMS surface roughness Sq was obtained for 
each image. The $S q$ values were averaged over four images and the standard deviations are given as errors.

\section{5. $Q C M-D$}

QCM-D experiments were performed using a QSense E4 from Biolin Scientific, Gothenburg, Sweden, at a temperature of $20^{\circ} \mathrm{C}$. Peptide adsorption at the different surfaces was measured in flow mode at a constant flow rate of $10 \mu \mathrm{L} /$ min provided by a peristaltic pump (IPC4, Ismatec, Wertheim, Germany). Due to the sometimes very small frequency shifts $(\Delta F)$, which were of the order of the drift of the QCM-D sensor, the recorded $\Delta F$ curves were drift-corrected in OriginPro, version 2020 (OriginLab Corporation, Northampton, MA, USA) by subtracting a linear function. In the following, only data for the 5th overtone are shown, while overtones 3 to 9 are shown in Figures S7-S12.

\section{Results and Discussion}

\subsection{Surface Characterization}

The topographies of the prepared $\mathrm{Au}, \mathrm{SiO}_{2}$ and $\mathrm{TiO}_{\mathrm{x}} / \mathrm{Ti}$ surfaces have been analyzed by means of AFM. The AFM image of the as-received Au surface presented in Figure 2a shows the individual grains of the polycrystalline electrode, which dominate the surface morphology. Deposition of the $\mathrm{SiO}_{2}$ and Ti thin films results in notable modifications of the overall surface topography. While larger grains are obtained after depositing the amorphous $\mathrm{SiO}_{2}$ film (Figure 2b), the oxidized Ti film exhibits a smoother surface (Figure 2c). This is also reflected in the calculated root-mean-square (RMS) roughness (Sq) values. Whereas $\mathrm{Sq}=3.09 \pm 0.14 \mathrm{~nm}$ for the uncoated $\mathrm{Au}$ electrode surface, $\mathrm{SiO}_{2}$ deposition results in a higher surface roughness of $\mathrm{Sq}=4.63 \pm 0.08 \mathrm{~nm}$. For the $\mathrm{TiO}_{x} / \mathrm{Ti}$ surface, however, a lower value of $S q=2.40 \pm 0.02 \mathrm{~nm}$ was determined. These differences can be attributed to different growth modes of these amorphous $\left(\mathrm{SiO}_{2}\right)$ and polycrystalline (Ti) films and the different deposition rates ( 0.07 vs. $0.16 \AA / s)$. Higher deposition rates typically result in rougher film topographies [23], which is in line with the present observations. Despite these notable differences in surface topography, we expect peptide adsorption to be predominantly affected by surface chemistry and not surface topography. This is mostly because the peptides studied in this work are very small in relation to the surface topographic features. Significant effects of nanoscale surface topography at this scale on biomolecular adsorption are typically observed only for larger proteins [21,24] or in the presence of strong peptide-peptide interactions which result in nanometer-sized aggregates [25]. However, because of the large Sq values of the surfaces, which are about one order of magnitude larger than those of silicon wafers [24], the adsorbed peptides with their small sizes and molecular weights below $2 \mathrm{kDa}$ cannot be identified by AFM [26,27].
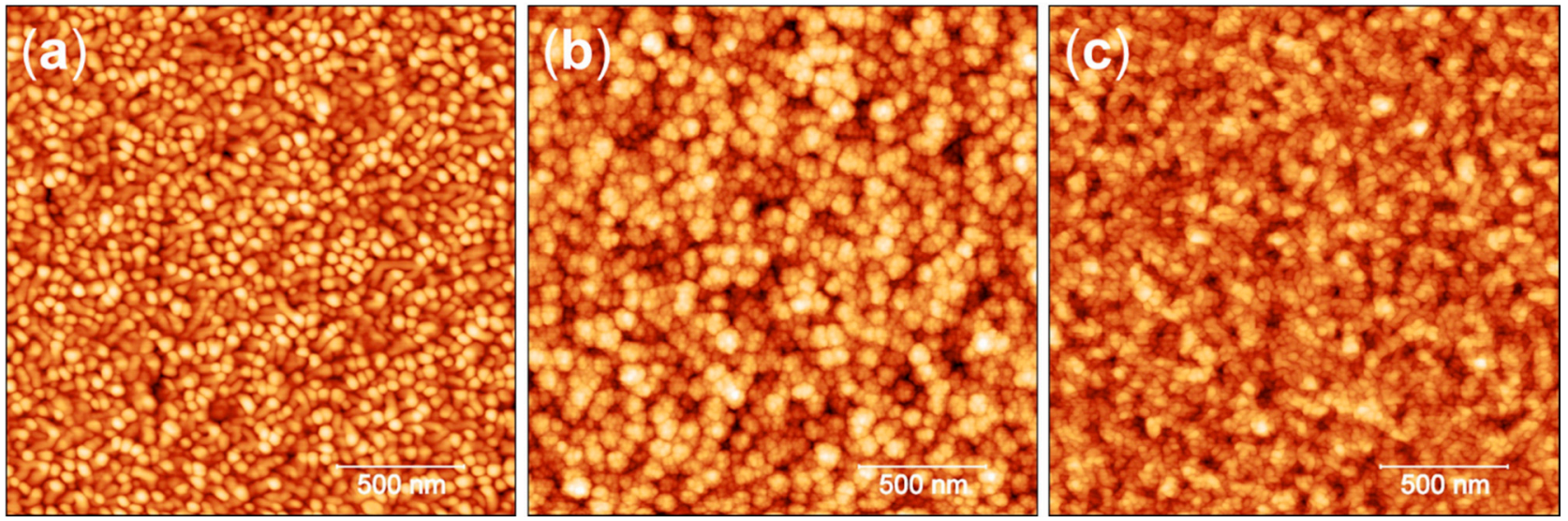

Figure 2. Representative AFM images of the employed (a) $\mathrm{Au},(\mathbf{b}) \mathrm{SiO}_{2}$, and (c) $\mathrm{TiO}_{\mathrm{x}} / \mathrm{Ti}$ surfaces. Height scales are $40 \mathrm{~nm}$ (a), $30 \mathrm{~nm}(\mathbf{b})$, and $20 \mathrm{~nm}$ (c), respectively. 
The chemical composition of the deposited films was assessed by XPS. The surface of the $\mathrm{SiO}_{2}$ film was found to be composed predominantly of silicon and oxygen with some contributions from adventitious carbon species (see Figure S1 and Table S1). The highresolution Si2p spectrum in Figure S2 additionally reveals only a single peak corresponding to $\mathrm{SiO}_{2}$ without any contributions from suboxides [28].

For the native surface oxide of the Ti thin film, only oxygen, titanium, carbon, and nitrogen are observed (see Figure S3 and Table S1), the latter two resulting from air exposure. More importantly, deconvolution of the Ti2p spectrum revealed that the surface oxide is mainly composed of $\mathrm{TiO}_{2}$ with only minor contributions from suboxides (see Figure $\mathrm{S} 4$ and Table S2). The O1s spectrum of the oxide-covered Ti film (see Figure S5) further indicates a significant hydroxylation of the ultra-thin surface oxide. In particular, deconvolution of the O1s spectrum reveals an $\mathrm{OH}^{-} / \mathrm{O}^{2-}$ ratio of $0.49 \pm 0.06$ (after subtraction of the $\mathrm{COOC}$ and $\mathrm{COOH}$ contributions; see Figure S6). Based on the energy difference between the oxide and the hydroxyl O1s contribution of $+1.5 \mathrm{eV}$, we conclude that these surface $\mathrm{OH}$ groups are acidic [29]. The surface hydroxylation is thus indicative of a significant negative surface charge formation above the isoelectric point caused by the deprotonation of surface OH groups.

\subsection{Peptide Adsorption}

The results of the QCM-D measurements (frequency shift, $\Delta F$, and change in dissipation, $\Delta D)$ are shown in Figure 3. For PAK(128-144) adsorption at the Au surface (Figure 3a, left panel), a sharp decrease of $\Delta F$ can be observed upon peptide injection, equivalent to an increase in sensor mass due to peptide adsorption at the electrode surface. This adsorption is accompanied by a rapid increase in the dissipation $\Delta D$. About 20 min after peptide injection, the decrease in $\Delta F$ is slowing down until a constant value of about $-10 \mathrm{~Hz}$ is eventually reached. At the same time, $\Delta D$ is decreasing again, resulting in a spike-like curve. Since $\Delta D$ is a measure of the viscoelasticity of the adsorbate film [30], such a behavior is indicative of structural rearrangements of the adsorbed peptides, resulting in a more compact film that traps fewer water molecules. This rearrangement appears to be a comparatively slow process that proceeds for more than $90 \mathrm{~min}$ without reaching a steady state. The compaction is partially reversed upon flushing the surface with peptide-free buffer solution, which results in a second, yet smaller, increase of $\Delta D$. After another $15 \mathrm{~min}$, $\Delta D$ saturates at an intermediate value. $\Delta F$, on the other hand, is barely affected by flushing, indicating that the majority of peptides are irreversibly adsorbed. The observed structural rearrangement in the adsorbed peptide film can be attributed to the high complexity of the amino acid sequence of the PAK(128-144) peptide, which features several different amino acid residues with very different properties (see Figure 1c). It is well known that the adsorption energies of different amino acids at Au surfaces can differ by a factor of two, with cysteine playing a special role due to its ability to form covalent bonds with the Au surface via its thiol group [31]. Therefore, it appears reasonable that the PAK(128-144) peptide, which contains two cysteines, undergoes significant conformational adjustments after adsorption that in turn affect the packing of the neighboring peptides and the availability of free adsorption sites.

This interpretation of residue-driven conformational changes is further supported by the fact that a rather similar behavior is also observed for the adsorption of PAO(128-144) at the Au surface (see Figure 3b, left panel). In this case, however, a larger frequency shift and a larger change in dissipation are observed. While it is rather tempting to attribute the considerably strong adsorption of both peptides at the Au surface to the formation of $\mathrm{S}-\mathrm{Au}$ bonds between the two cysteines and the Au surface, these differences in adsorbed mass underscore the relevance of the other residues. As shown in Figure 1c, the amino acid sequences of both peptides differ in eight residues. Using adsorption energies for isolated but capped amino acids at $\mathrm{Au}$ [31], we calculated the adsorption energies $E_{\text {ads }}$ (PAK) and $E_{\mathrm{ads}}(\mathrm{PAO})$ for both peptides. We found that the calculated adsorption energy of $\operatorname{PAK}(128-144)$ is slightly lower than that of $\mathrm{PAO}(128-144)$, i.e., $E_{\mathrm{ads}}(\mathrm{PAK})=-1488.0 \mathrm{~kJ} / \mathrm{mol}$ 
and $E_{\text {ads }}(\mathrm{PAO})=-1457.7 \mathrm{~kJ} / \mathrm{mol}$, which is at variance with the above experiments that showed stronger adsorption of PAO. This discrepancy can be attributed to two factors that are not considered in this simple calculation. First, the published adsorption energies of the amino acids are for adsorption at a flat $\mathrm{Au}(111)$ surface in vacuum [31], while our experiments were performed at a polycrystalline $\mathrm{Au}$ surface in physiological buffer. The presence of water, ions, and additional crystal facets may alter the adsorption energies of individual amino acids in a species-dependent manner. Therefore, we next calculated the grand average of hydropathicity (GRAVY) [32] for both peptides (see Figure 1c). As it turns out, PAO(128-144) is slightly more hydrophobic than PAK(128-144). Since non-oxidized Au surfaces in general have a somewhat hydrophobic character [33], this slight increase in peptide hydrophobicity may indeed result in stronger adsorption, even though both peptides are still rather hydrophilic in nature.
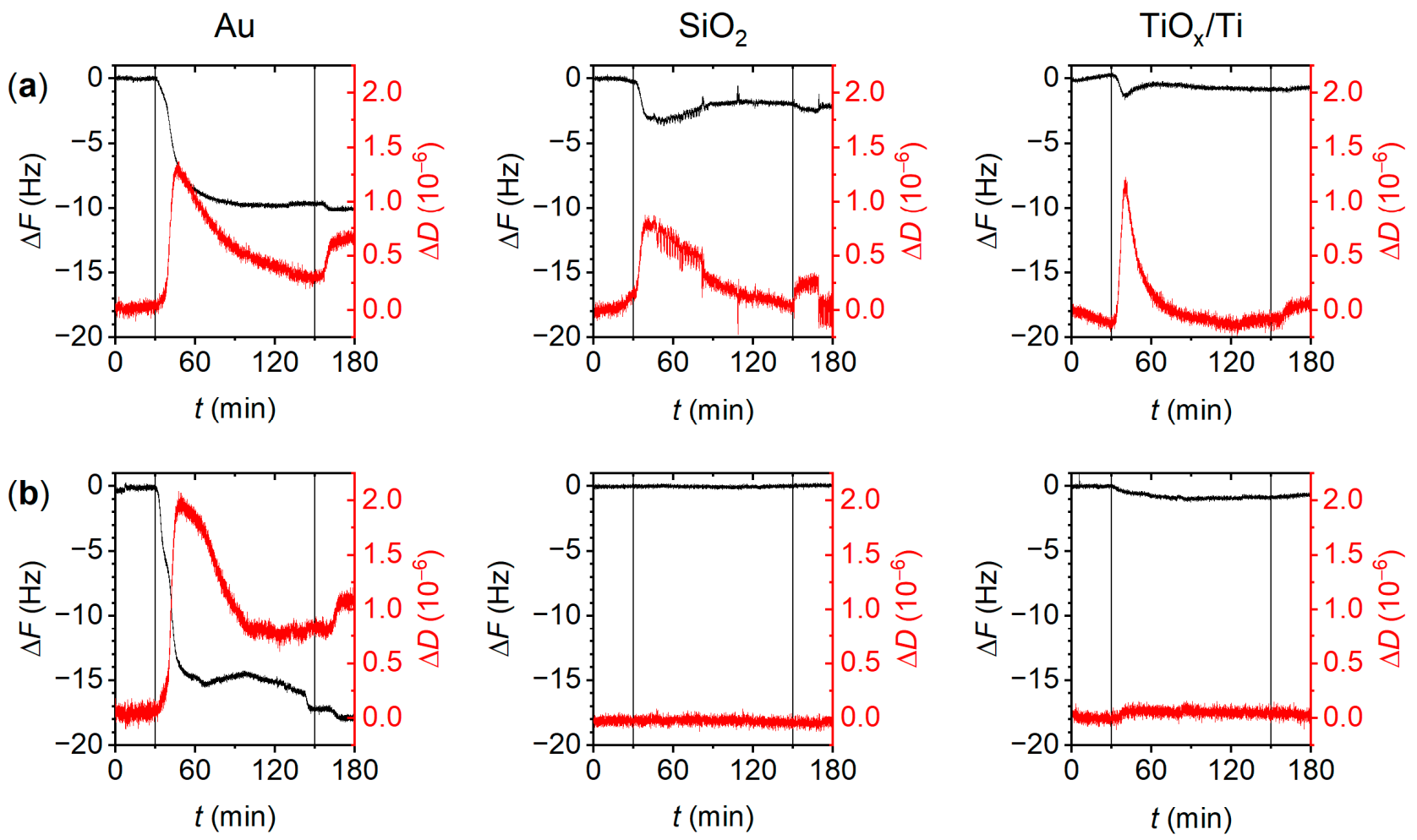

Figure 3. Frequency shift $\Delta F$ (left axes) and change in dissipation $\Delta D$ (right axes) for the adsorption of (a) PAK(128-144) and (b) $\mathrm{PAO}(128-144)$ at the $\mathrm{Au}$ (left), $\mathrm{SiO}_{2}$ (center), and $\mathrm{TiO}_{\mathrm{x}} / \mathrm{Ti}$ surface (right). Vertical lines indicate the time points of peptide injection and flushing with peptide-free buffer.

Another important factor that has been neglected in the above considerations is the conformation of the two peptides. In particular, both peptides used in the present study feature two cysteines close to their termini, which are expected to form disulfide bridges and thus facilitate the formation of a peptide loop similar to that observed in the full pilin protein (see Figure 1b). Loop formation will most likely restrict the mobility of the amino acid sidechains and thereby affect their interaction with the Au surface. Furthermore, changes in amino acid sequence will also affect the conformation and stability of the loop itself [34]. This in particular concerns the presence of prolines [35], of which $\mathrm{PAO}(128-144)$ features an additional one between the two cysteines (see Figure 1c). Indeed, structural investigations of the complete PAK and PAO pilin proteins revealed small but significant differences in loop conformation [14].

For the $\mathrm{SiO}_{2}$ surface, adsorption of both peptides is strongly reduced. At this surface, peptide adsorption obviously does not involve covalent bond formation. Furthermore, peptide adsorption also requires the displacement of water molecules from the surface- 
bound hydration layer [36]. Both of these effects may contribute to weakening peptide adsorption. However, there are also notable differences between the two peptides. For PAK(128-144), similar trends as for the Au surface are observed for $\Delta F$ and $\Delta D$, albeit with much smaller absolute values (Figure 3a, central panel). Interestingly, a slight overshooting in the adsorbed mass is observed, with $\Delta F$ dropping to about $-3 \mathrm{~Hz}$ within the first $10 \mathrm{~min}$ of adsorption, after which it slowly recovers and finally saturates at about $-2 \mathrm{~Hz}$. This overshooting is again indicative of structural rearrangements occurring in the adsorbate film, which now appear to be substantially different from those at the Au surface where no overshooting was observed (Figure 3a, left panel). Furthermore, the overall adsorbed mass at equilibrium is significantly smaller for the $\mathrm{SiO}_{2}$ than for the Au surface.

For $\mathrm{PAO}(128-144)$, on the other hand, barely any adsorption at the $\mathrm{SiO}_{2}$ surface can be detected (Figure $3 b$, central panel). This observation is rather surprising since protein and peptide adsorption at $\mathrm{SiO}_{2}$ surfaces, which are negatively charged under physiological conditions [37], is mostly driven by electrostatic interactions [24,25,38,39]. The studied peptides, on the other hand, both have essentially the same isoelectric points and should thus have a negative net charge of about -1 at $\mathrm{pH} 7.4$ (see Figure 1c). Nevertheless the peptide sequences shown in Figure 1c reveal that PAK(128-144) features three positively and three negatively charged amino acid residues, whereas PAO(128-144) has only two of each. Furthermore, the negatively charged residues in PAK(128-144) are all clustered within a short loop region (aa 132 to 134), while the positively charged ones are located close to the termini and thus end up in the stem region (see Figure 4a). Considering the dimensions of the peptide loop and the short Debye length of PBS of $\lambda_{\mathrm{D}} \sim 0.7 \mathrm{~nm}$ [40], we assume that this peptide initially adsorbs in an upright configuration, in which two to three of the positively charged residues are in close contact with the negatively charged $\mathrm{SiO}_{2}$ surface (see Figure 4a). In this geometry, the negatively charged residues are located more than $0.7 \mathrm{~nm}$ from the like-charged surface, so that electrostatic repulsion is effectively screened by the electrolyte. Later, however, short-range van der Waals interactions may take over and result in the peptide loop assuming a flat orientation (see Figure $4 \mathrm{~b}$ ), which may be the structural rearrangements observed in the corresponding $\Delta D$ curve. In contrast, the charged residues in the $\mathrm{PAO}(128-144)$ sequence are more evenly distributed (see Figure 1c), so that this mechanism will be less effective, resulting in weaker adsorption as observed experimentally (see Figure 3).

(a)

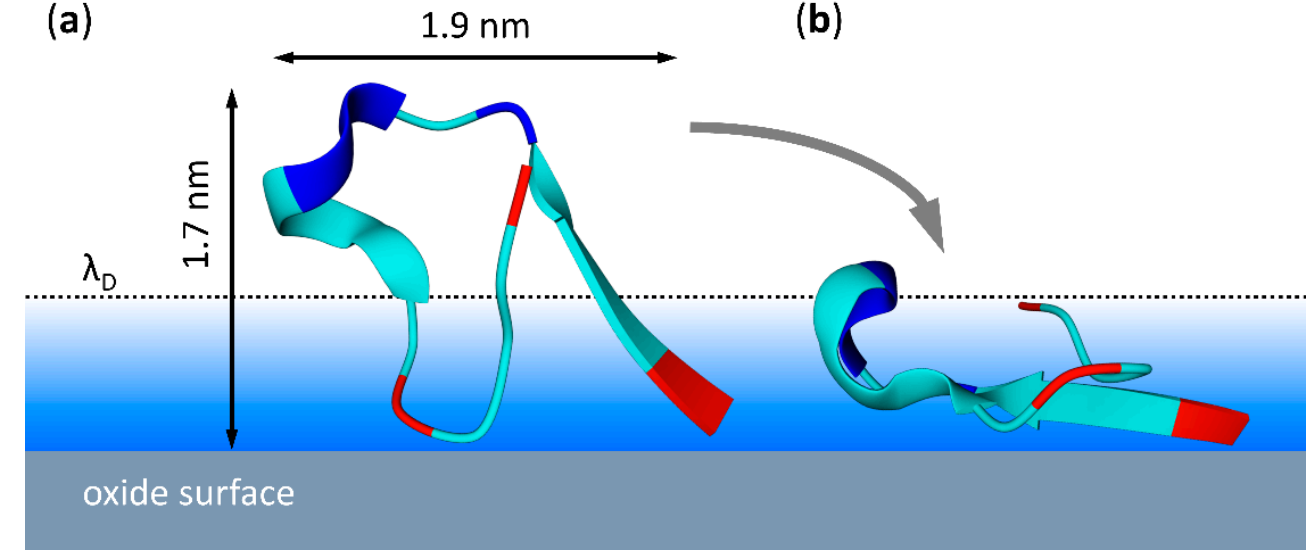

Figure 4. Proposed adsorption geometry for $\mathrm{PAK}(128-144)$ at the $\mathrm{SiO}_{2}$ surface. (a) Initial adsorption occurs in an upright conformation with the positively (red) and negatively charged (blue) amino acid residues being located within and beyond the Debye length $\lambda_{\mathrm{D}}$, respectively. (b) Subsequently, short-range van der Waals interactions may result in the peptide loop assuming a flat geometry. Structure of the PAK(128-144) peptide loop taken from the RCSB PDB (rcsb.org), PDB ID 1OQW [15]. The images were created using $\mathrm{Mol}^{*}$ Viewer [18]. 
At the $\mathrm{TiO}_{\mathrm{x}} / \mathrm{Ti}$ surface, PAK(128-144) shows a similar adsorption behavior as at the $\mathrm{SiO}_{2}$ surface, including the overshooting in adsorbed mass (Figure 3a, right panel). However, the absolute frequency shifts $\Delta F$ are even smaller than for the $\mathrm{SiO}_{2}$ surface, with values of about $-1.4 \mathrm{~Hz}$ and $-0.5 \mathrm{~Hz}$ at the peak and in equilibrium, respectively. Nevertheless, the spike in the $\Delta D$ curve is higher and sharper than in the previous case, which indicates that structural rearrangements are faster and more pronounced. This is in line with the proposed model of PAK(128-144) adsorption in Figure 4 because $\mathrm{TiO}_{2}$ has a significantly larger Hamaker constant than $\mathrm{SiO}_{2}$ [41] so that van der Waals interactions should be more dominant at the $\mathrm{TiO}_{x} / \mathrm{Ti}$ surfaces and thus result in the peptide assuming the flat configuration in shorter time. In contrast, adsorption of $\mathrm{PAO}(128-144)$ at the $\mathrm{TiO}_{\mathrm{x}} / \mathrm{Ti}$ surface shows a frequency shift in equilibrium that is comparable to that of PAK(128-144) with no indication of an overshooting (Figure 3b, right panel). In addition, the $\Delta D$ curve shows only a very small change upon adsorption without any visible spike. This indicates that this particular peptide immediately assumes a flat conformation at the $\mathrm{TiO}_{x} /$ Ti surface upon adsorption without any subsequent rearrangements. This rather pronounced difference to $\mathrm{PAO}(128-144)$ adsorption at the $\mathrm{SiO}_{2}$ surface where barely any adsorption was observed may be a result of the stronger van der Waals interactions in combination with slightly reduced electrostatic repulsion. Although the isoelectric points of both $\mathrm{SiO}_{2}$ and $\mathrm{TiO}_{2}$ can vary quite drastically between different material formulations, the one of $\mathrm{TiO}_{2}$ should, on average, be higher [42] and may thus result in a less negatively charged surface at $\mathrm{pH}$ 7.4. The reduced electrostatic repulsion may enable the $\mathrm{PAO}(128-144)$ peptide, which has a more neutral character than PAK(128-144) because of its more evenly distributed charges (see Figure 1c), to get closer to the surface. Then, the attractive van der Waals interactions will take over and result in the adsorption of the peptide in a flat conformation.

Finally, we quantified the irreversibly adsorbed peptide mass after flushing. In the stationary regime after flushing, the obtained $\Delta D$ values in all cases are rather low with $\Delta D \leq 1.1 \times 10^{-6}$, while the spread between individual overtones is very small as well (see Figures S7-S12). Therefore, we calculated the irreversibly adsorbed mass using the Sauerbrey relation [30,43]. This was done by first individually averaging the $\Delta F$ values recorded for overtones 3 to 9 in the time window from 20 to $30 \mathrm{~min}$ after flushing. Figure 5a presents the averages of the four different overtones for each peptide-surface combination with the standard deviations as errors. As can be seen, the trends of the irreversibly adsorbed mass reflect the overall trends seen in the $\Delta F$ data reported in Figure 3 rather well, despite minor deviations and the sometimes rather large error bars, which result from measurement artefacts and, in particular, variations between individual overtones (see Figures S7-S12).

Based on the determined Sauerbrey masses shown in Figure $5 \mathrm{a}$, we further attempted to estimate the equilibrium surface coverage for the different peptide-surface combinations. For this, the footprint of each adsorbed peptide must be calculated. This was done by estimating their hydrodynamic radii $r_{\mathrm{H}}$ using the empiric formula developed by Nobbmann [44]. For both peptides, this results in $r_{\mathrm{H}} \sim 0.8 \mathrm{~nm}$, which is in fair agreement with the dimensions of the peptide loop in the complete pilin protein (see Figure 4). Using this value for surface coverage estimation thus corresponds to the assumption of the intact peptide loops lying flat on the surface. As can be seen in Figure 5b, this rather crude estimation reveals a surface coverage of about one monolayer for PAK(128-144) at the Au surface. In line with the increased Sauerbrey mass, PAO(128-144) shows about twice this coverage. While such a double-layer coverage is certainly possible, it may just as well be a result of $\mathrm{PAO}(128-144)$ adsorbing in a more upright instead of a flat configuration. In contrast, for the oxide surfaces, surface coverage is well below one monolayer, i.e., 0.04 to $0.15 \mathrm{ML}$. At such a low coverage, a flat adsorption geometry as suggested in Figure 4 appears certainly possible. 

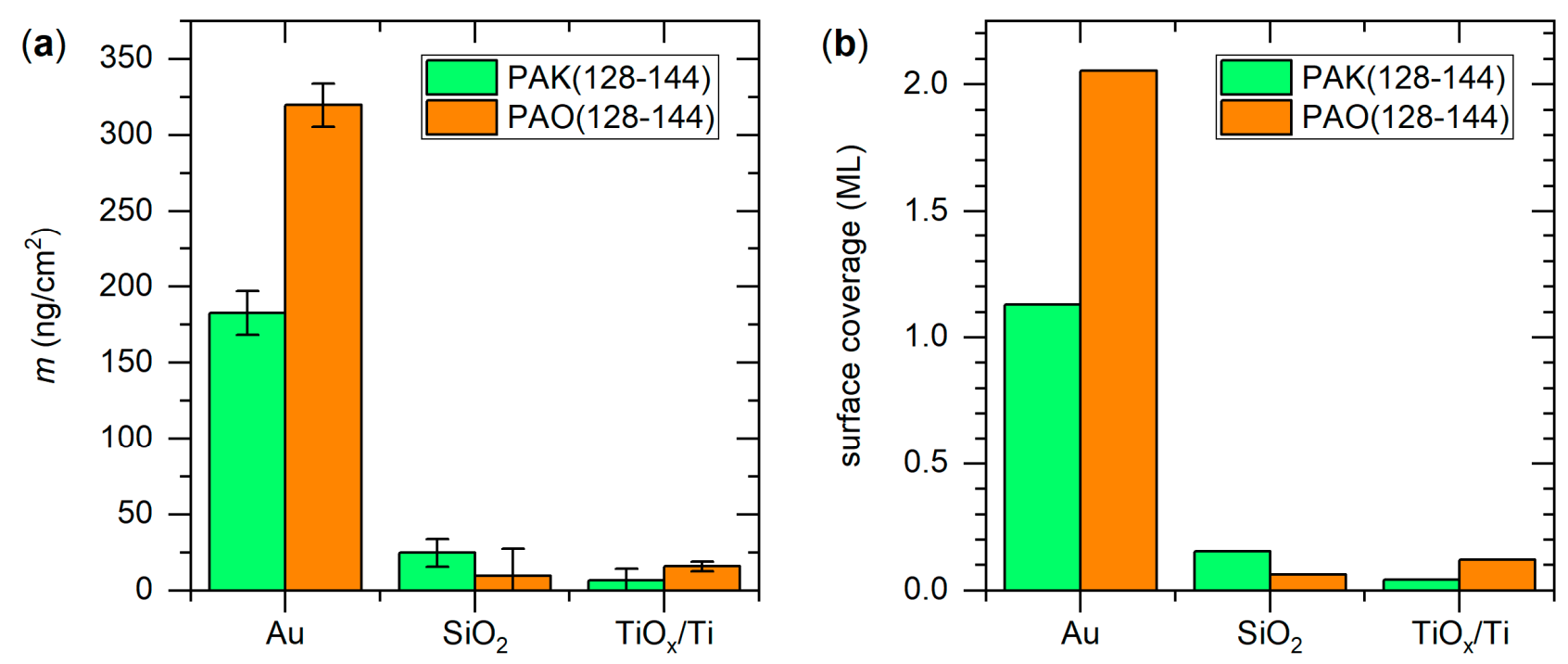

Figure 5. (a) Irreversibly adsorbed peptide mass $m$ determined for the different peptide-surface combinations using the Sauerbrey equation. Values represent averages of overtones 3 to 9 with the standard deviations as error bars. (b) Corresponding surface coverage in monolayers (ML) calculated from the molecular weights and the estimated hydrodynamic radii $r_{\mathrm{H}}$ of the peptides.

\section{Conclusions}

In this work, we investigated the adsorption of two P. aeruginosa-derived pilin peptides with sequences corresponding to the receptor-binding domains of the two strains PAK and PAO at three abiotic surfaces using QCM-D. Strongest adsorption of both peptides is observed at the Au surface, which is accompanied by strong structural rearrangements of the adsorbed peptide films. While adsorption at this surface probably involves covalent $\mathrm{S}-\mathrm{Au}$ bond formation between the peptides' cysteins and the surface, the large differences in adsorbed peptide mass (see Figure 5) suggest that the other amino acid residues and the exact conformation of the peptide loop play important roles in adsorption as well. At oxide surfaces, adsorption of both peptides is drastically reduced and most likely driven by electrostatic and van der Waals interactions. However, also in this case, the peptide-specific and material-specific differences in adsorption hint at the importance of the exact peptide conformation and possibly the clustering of charged amino acid residues on opposing sides of the loop in the case of PAK(128-144). Our work thus suggests that colonization of abiotic surfaces by $P$. aeruginosa and most likely other pathogenic microbes is highly dependent on the surface material and the microbial strain, with comparatively small sequence variations potentially having a strong effect on initial adhesion. Finally, our results also highlight the importance of molecular-level investigations to understand and ultimately control microbial colonization of the surfaces of medical implants as well as everyday materials and devices.

Supplementary Materials: The following are available online at https:/ / www.mdpi.com/article/10 .3390 / micro1010010/s1, Figure S1: Ex-situ XPS survey of the $\mathrm{SiO}_{2}$ film, Figure S2: Ex-situ XPS Si2p high-resolution spectrum of the $\mathrm{SiO}_{2}$ film, Figure S3: Ex-situ XPS survey of the $\mathrm{TiO}_{\mathrm{x}} / \mathrm{Ti}$ film, Table S1. XPS quantification results for the $\mathrm{SiO}_{2}$ and $\mathrm{TiO}_{x} / \mathrm{Ti}$ films, Figure S4: Ex-situ XPS Ti2p high-resolution spectrum of the $\mathrm{TiO}_{x} / \mathrm{Ti}$ film, Table S2. Results of the Ti 2p deconvolution, Figure S5: Ex-situ XPS O1s high-resolution spectrum of the $\mathrm{TiO}_{\mathrm{x}} / \mathrm{Ti}$ film, Figure S6: Ex-situ XPS C1s high-resolution spectrum of the $\mathrm{TiO}_{x} / \mathrm{Ti}$ film, Figure S7: QCM-D results (overtones 3 to 9) for PAK(128-144) adsorption at the Au surface, Figure S8: QCM-D results (overtones 3 to 9) for PAO(128-144) adsorption at the Au surface, Figure S9: QCM-D results (overtones 3 to 9) for PAK(128-144) adsorption at the $\mathrm{SiO}_{2}$ surface, Figure S10: QCM-D results (overtones 3 to 9) for PAO(128-144) adsorption at the $\mathrm{SiO}_{2}$ surface, Figure S11: QCM-D results (overtones 3 to 9) for PAK(128-144) adsorption at the $\mathrm{TiO}_{\mathrm{x}} / \mathrm{Ti}$ 
surface, Figure S12: QCM-D results (overtones 3 to 9) for PAO(128-144) adsorption at the $\mathrm{TiO}_{\mathrm{x}} / \mathrm{Ti}$ surface.

\begin{abstract}
Author Contributions: Data curation, Y.Y., S.S. and A.K.; formal analysis, Y.Y., S.S. and A.K.; investigation, Y.Y. and S.S.; methodology, Y.Y., S.S., G.G. and A.K.; resources, G.G.; supervision, G.G. and A.K.; validation, Y.Y., S.S. and A.K.; visualization, Y.Y., S.S. and A.K.; writing-original draft, A.K.; writing-review and editing, Y.Y., S.S., G.G. and A.K. All authors have read and agreed to the published version of the manuscript.
\end{abstract}

Funding: This research received no external funding.

Data Availability Statement: The data presented in this study are available on request from the corresponding author.

Conflicts of Interest: The authors declare no conflict of interest.

\title{
References
}

1. Hedrick, T.L.; Adams, J.D.; Sawyer, R.G. Implant-associated infections: An overview. J. Long Term Eff. Med. Implant. 2006, 16, 83-99. [CrossRef]

2. Busscher, H.J.; van der Mei, H.C.; Subbiahdoss, G.; Jutte, P.C.; van den Dungen, J.J.A.M.; Zaat, S.A.J.; Schultz, M.J.; Grainger, D.W. Biomaterial-associated infection: Locating the finish line in the race for the surface. Sci. Transl. Med. 2012, 4, 153rv10. [CrossRef]

3. Laxminarayan, R.; Duse, A.; Wattal, C.; Zaidi, A.K.M.; Wertheim, H.F.L.; Sumpradit, N.; Vlieghe, E.; Hara, G.L.; Gould, I.M.; Goossens, H.; et al. Antibiotic resistance-The need for global solutions. Lancet Infect. Dis. 2013, 13, 1057-1098. [CrossRef]

4. Levy, S.B.; Marshall, B. Antibacterial resistance worldwide: Causes, challenges and responses. Nat. Med. 2004, 10, S122-S129. [CrossRef] [PubMed]

5. Taubes, G. The bacteria fight back. Science 2008, 321, 356-361. [CrossRef] [PubMed]

6. Alt, V. Antimicrobial coated implants in trauma and orthopaedics-A clinical review and risk-benefit analysis. Injury 2017, 48, 599-607. [CrossRef] [PubMed]

7. Salwiczek, M.; Qu, Y.; Gardiner, J.; Strugnell, R.A.; Lithgow, T.; McLean, K.M.; Thissen, H. Emerging rules for effective antimicrobial coatings. Trends Biotechnol. 2014, 32, 82-90. [CrossRef] [PubMed]

8. Souli, M.; Galani, I.; Giamarellou, H. Emergence of extensively drug-resistant and pandrug-resistant Gram-negative bacilli in Europe. Euro. Surveill. 2008, 13, 19045. [CrossRef]

9. Livermore, D.M. Multiple mechanisms of antimicrobial resistance in Pseudomonas aeruginosa: Our worst nightmare? Clin. Infect. Dis. 2002, 34, 634-640. [CrossRef]

10. Willyard, C. The drug-resistant bacteria that pose the greatest health threats. Nature 2017, 543, 15. [CrossRef]

11. Craig, L.; Forest, K.T.; Maier, B. Type IV pili: Dynamics, biophysics and functional consequences. Nat. Rev. Microbiol. 2019, 17, 429-440. [CrossRef] [PubMed]

12. Craig, L.; Pique, M.E.; Tainer, J.A. Type IV pilus structure and bacterial pathogenicity. Nat. Rev. Microbiol. $2004,2,363-378$. [CrossRef]

13. Hahn, H.P. The type-4 pilus is the major virulence-associated adhesin of Pseudomonas aeruginosa-A review. Gene 1997, 192, 99-108. [CrossRef]

14. Giltner, C.L.; van Schaik, E.J.; Audette, G.F.; Kao, D.; Hodges, R.S.; Hassett, D.J.; Irvin, R.T. The Pseudomonas aeruginosa type IV pilin receptor binding domain functions as an adhesin for both biotic and abiotic surfaces. Mol. Microbiol. 2006, 59, 1083-1096. [CrossRef] [PubMed]

15. Craig, L.; Taylor, R.K.; Pique, M.E.; Adair, B.D.; Arvai, A.S.; Singh, M.; Lloyd, S.J.; Shin, D.S.; Getzoff, E.D.; Yeager, M.; et al. Type IV Pilin Structure and Assembly. Mol. Cell 2003, 11, 1139-1150. [CrossRef]

16. Hench, L.L. The story of Bioglass. J. Mater. Sci. Mater. Med. 2006, 17, 967-978. [CrossRef]

17. Geetha, M.; Singh, A.K.; Asokamani, R.; Gogia, A.K. Ti based biomaterials, the ultimate choice for orthopaedic implants-A review. Prog. Mat. Sci. 2009, 54, 397-425. [CrossRef]

18. Sehnal, D.; Bittrich, S.; Deshpande, M.; Svobodová, R.; Berka, K.; Bazgier, V.; Velankar, S.; Burley, S.K.; Koča, J.; Rose, A.S. $\mathrm{Mol}^{*}$ Viewer: Modern web app for 3D visualization and analysis of large biomolecular structures. Nucleic Acids Res. 2021, 49, W431-W437. [CrossRef]

19. Lear, S.; Cobb, S.L. Pep-Calc.com: A set of web utilities for the calculation of peptide and peptoid properties and automatic mass spectral peak assignment. J. Comput. Aided Mol. Des. 2016, 30, 271-277. [CrossRef]

20. Gasteiger, E.; Hoogland, C.; Gattiker, A.; Duvaud, S.; Wilkins, M.R.; Appel, R.D.; Bairoch, A. Protein Identification and Analysis Tools on the ExPASy Server. In The Proteomics Protocols Handbook; Walker, J.M., Ed.; Humana Press: Totowa, NJ, USA, 2005; pp. 571-607. ISBN 978-1-58829-343-5.

21. Yang, Y.; Knust, S.; Schwiderek, S.; Qin, Q.; Yun, Q.; Grundmeier, G.; Keller, A. Protein Adsorption at Nanorough Titanium Oxide Surfaces: The Importance of Surface Statistical Parameters beyond Surface Roughness. Nanomaterials 2021, 11, 357. [CrossRef]

22. Nečas, D.; Klapetek, P. Gwyddion: An open-source software for SPM data analysis. Open Phys. 2012, 10, 181-188. [CrossRef] 
23. Amirzada, M.R.; Tatzel, A.; Viereck, V.; Hillmer, H. Surface roughness analysis of $\mathrm{SiO}_{2}$ for PECVD, PVD and IBD on different substrates. Appl. Nanosci. 2016, 6, 215-222. [CrossRef]

24. Yang, Y.; Yu, M.; Böke, F.; Qin, Q.; Hübner, R.; Knust, S.; Schwiderek, S.; Grundmeier, G.; Fischer, H.; Keller, A. Effect of nanoscale surface topography on the adsorption of globular proteins. Appl. Surf. Sci. 2021, 535, 147671. [CrossRef]

25. Hanke, M.; Yang, Y.; Ji, Y.; Grundmeier, G.; Keller, A. Nanoscale Surface Topography Modulates hIAPP Aggregation Pathways at Solid-Liquid Interfaces. Int. J. Mol. Sci. 2021, 22, 5142. [CrossRef]

26. Hajiraissi, R.; Hanke, M.; Gonzalez Orive, A.; Duderija, B.; Hofmann, U.; Zhang, Y.; Grundmeier, G.; Keller, A. Effect of Terminal Modifications on the Adsorption and Assembly of hIAPP(20-29). ACS Omega 2019, 4, 2649-2660. [CrossRef] [PubMed]

27. Hajiraissi, R.; Hanke, M.; Yang, Y.; Duderija, B.; Gonzalez Orive, A.; Grundmeier, G.; Keller, A. Adsorption and Fibrillization of Islet Amyloid Polypeptide at Self-Assembled Monolayers Studied by QCM-D, AFM, and PM-IRRAS. Langmuir 2018, 34, 3517-3524. [CrossRef]

28. Himpsel, F.J.; McFeely, F.R.; Taleb-Ibrahimi, A.; Yarmoff, J.A.; Hollinger, G. Microscopic structure of the $\mathrm{SiO}_{2} / \mathrm{Si}$ interface. Phys. Rev. B 1988, 38, 6084-6096. [CrossRef] [PubMed]

29. Benkoula, S.; Sublemontier, O.; Patanen, M.; Nicolas, C.; Sirotti, F.; Naitabdi, A.; Gaie-Levrel, F.; Antonsson, E.; Aureau, D.; Ouf, F.-X.; et al. Water adsorption on $\mathrm{TiO}_{2}$ surfaces probed by soft X-ray spectroscopies: Bulk materials vs. isolated nanoparticles. Sci. Rep. 2015, 5, 15088. [CrossRef]

30. Dixon, M.C. Quartz crystal microbalance with dissipation monitoring: Enabling real-time characterization of biological materials and their interactions. J. Biomol. Tech. 2008, 19, 151-158. [PubMed]

31. Futera, Z. Amino-acid interactions with the $\mathrm{Au}(111)$ surface: Adsorption, band alignment, and interfacial electronic coupling. Phys. Chem. Chem. Phys. 2021, 23, 10257-10266. [CrossRef]

32. Kyte, J.; Doolittle, R.F. A simple method for displaying the hydropathic character of a protein. J. Mol. Biol. 1982, 157, 105-132. [CrossRef]

33. Canning, J.; Tzioumis, N.; Tzoumis, N.; Beattie, J.K.; Gibson, B.C.; Ilagan, E. Water on Au sputtered films. Chem. Commun. 2014, 50, 9172-9175. [CrossRef]

34. Zhang, R.M.; Snyder, G.H. Dependence of formation of small disulfide loops in two-cysteine peptides on the number and types of intervening amino acids. J. Biol. Chem. 1989, 264, 18472-18479. [CrossRef]

35. Krieger, F.; Möglich, A.; Kiefhaber, T. Effect of proline and glycine residues on dynamics and barriers of loop formation in polypeptide chains. J. Am. Chem. Soc. 2005, 127, 3346-3352. [CrossRef]

36. Ley, K.; Christofferson, A.; Penna, M.; Winkler, D.; Maclaughlin, S.; Yarovsky, I. Surface-water Interface Induces Conformational Changes Critical for Protein Adsorption: Implications for Monolayer Formation of EAS Hydrophobin. Front. Mol. Biosci. 2015, 2, 64. [CrossRef]

37. Dove, P.M.; Craven, C.M. Surface charge density on silica in alkali and alkaline earth chloride electrolyte solutions. Geochim. Cosmochim. Acta 2005, 69, 4963-4970. [CrossRef]

38. McUmber, A.C.; Randolph, T.W.; Schwartz, D.K. Electrostatic Interactions Influence Protein Adsorption (but Not Desorption) at the Silica-Aqueous Interface. J. Phys. Chem. Lett. 2015, 6, 2583-2587. [CrossRef] [PubMed]

39. Meissner, J.; Prause, A.; Bharti, B.; Findenegg, G.H. Characterization of protein adsorption onto silica nanoparticles: Influence of $\mathrm{pH}$ and ionic strength. Colloid Polym. Sci. 2015, 293, 3381-3391. [CrossRef] [PubMed]

40. Chu, C.-H.; Sarangadharan, I.; Regmi, A.; Chen, Y.-W.; Hsu, C.-P.; Chang, W.-H.; Lee, G.-Y.; Chyi, J.-I.; Chen, C.-C.; Shiesh, S.-C.; et al. Beyond the Debye length in high ionic strength solution: Direct protein detection with field-effect transistors (FETs) in human serum. Sci. Rep. 2017, 7, 5256. [CrossRef] [PubMed]

41. Ackler, H.D.; French, R.H.; Chiang, Y.-M. Comparisons of Hamaker Constants for Ceramic Systems with Intervening Vacuum or Water: From Force Laws and Physical Properties. J. Colloid Interface Sci. 1996, 179, 460-469. [CrossRef]

42. Kosmulski, M. The pH-dependent surface charging and points of zero charge: V. Update. J. Colloid Interface Sci. 2011, 353, 1-15. [CrossRef]

43. Sauerbrey, G. Verwendung von Schwingquarzen zur Wägung dünner Schichten und zur Mikrowägung. Z. Physik 1959, 155, 206-222. [CrossRef]

44. Nobbmann, U. Characterization down to Nanometers: Light Scattering from Proteins and Micelles. In Mesoscale Phenomena in Fluid Systems; Case, F., Alexandridis, P., Eds.; American Chemical Society: Washington, DC, USA, 2003; pp. 44-59, ISBN 9780841238671. 